\title{
Mathematical modeling of thermal fire effect on tanks with oil products
}

\author{
Mykhailo Semerak ${ }^{1}$, Sergii Pozdeev ${ }^{2}$, Roman Yakovchuk ${ }^{1, *}$, Olga Nekora $^{2}$ and Oleksandr \\ Sviatkevych $^{3}$ \\ ${ }^{1}$ Lviv Polytechnic National University, Lviv, Ukraine \\ ${ }^{2}$ Cherkassy Institute of Fire Safety named after Heroes of Chornobyl of National University of Civil \\ Defense of Ukraine, Cherkassy, Ukraine \\ ${ }^{3}$ Lviv State University of Life Safety, Lviv, Ukraine
}

\begin{abstract}
The aim of the work is the development of mathematical models for research that allows to determine the ultimate indicators of the thermal effect on tanks with oil products in a fire. A calculation method was developed to implement the calculation for various scenarios for the development of a fire in a tank with oil. After the calculations, the results of mathematical modeling of the temperature on the walls of the reservoir in the conditions of a fire in neighboring reservoirs in the form of temperature distributions were obtained. Analysis of the temperature distributions showed that the most dangerous scenario is when the fire occurs according to scheme No. 3 in the case of burning an oil torch at a temperature of $1500 \mathrm{~K}$. In each case, the maximum temperature of heating the tank wall is almost unaffected by the oil, which is confirmed by the curves of the maximum temperature curves heating of the reservoir wall, depending on the time of fire impact on adjacent tanks. The maximum temperature of the reservoir wall was determined at the place of its connection with the oil product, it is preserved.
\end{abstract}

\section{Introduction}

The increase in consumption of energetic resources, including oil products and of the combustible liquids requires dealing with actual research-practice tasks of providing fire safety of objects, their reservation and transportation. One of such tasks is development of mathematical models for calculation, which allows to determine the boundary index of thermal effect on construction of oil products tanks during the fire. Thus, there is a necessity in usage of mathematical modelling methods, which allow to get necessary parameters precisely and reliably for all of construction's elements under study.

The appearance and development of fire in a tank depends on the following factors: presence of explosive concentration of oil (oil products) vapor inside and outside the tank, presence of ignition source, constructive characteristics of tank as well as the schemes of mutual situation of tanks in tank park.

\footnotetext{
* Corresponding author: yakovchukrs@ukr.net
} 
One of the most important parameters, which characterizes development of fire in a tank, is the heat fire mode. The character of temperature distribution in liquid capacity as well as oil product tank's wallsides differs depending on physicochemical characteristics of combustible liquids [1].

There are recommendations for the design of reservoirs in oil reservoirs [2]. If we consider the heat exchange thermal processes in the tank with flare fire on board tanks, you will notice that this problem has a complex setting and requires the involvement of compatible models Thermogasdynamics, thermal conductivity and models of wall surface layers to the surface of the walls of the tank, which is subjected to heat exposure. The problem is compounded by the fact that in addition to these models, you need to draw for the complex circuit patterns integrated model of radiant heat exchange. This means that this problem can be solved only numerically using specialized computer systems that enable this analysis tasks compatible thermodynamics. To avoid a significant complication of the problem during saving the appropriate accuracy and reliability, we have made several assumptions that simplify the model. Assumptions for simplification have following statements.

1. A fire in an adjacent tank is developed and is shaped like a torch height of $15 \mathrm{~m}$ with a conical surface temperature averaged a constant, which is $T_{\mathrm{f}}$.

2. Heat exchange, between torches and tanks fire and tanks walls, also in the tank's cavity has only radial in nature, since the impact of heat exchange convective is much smaller.

3. Thermal properties of the tanks steel walls can depend on the temperature.

4. The cause and course of the fire in the early period is not considered.

5. The temperature of the tanks wall and the fire temperature is the same, and the tanks wall is also involved in radiant heat exchange.

The source of heat exposure in modeling is a torch under the tank during the fire which has geometrical parameters corresponding to the circuit, which is shown in Fig.1

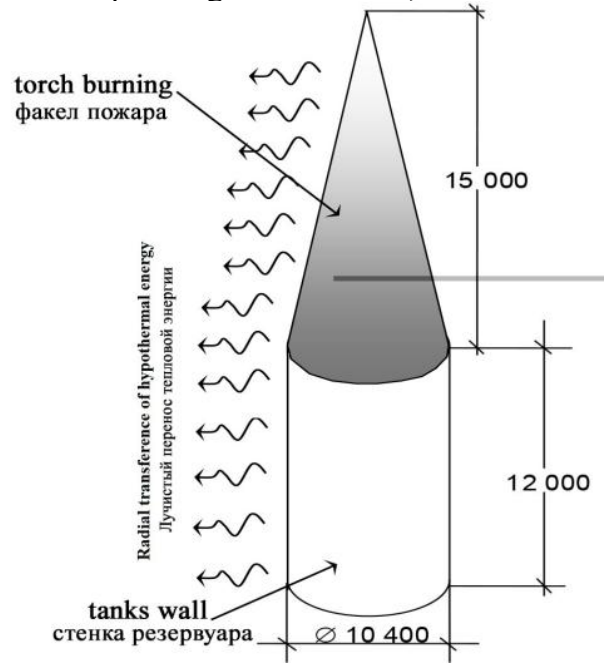

Fig. 1. Torch location under the tank on fire.

Using the circuit of thermal effects of fire on the tank was considered four scenarios of fire. These cases are in different situations of oil products ignition on the adjacent tanks to the tank, the thermal effect of fire which is being studied. Fig. 2 show us the thermal effects of fire on the tank which is being studied in compliance with the third scenario (most dangerous) of fire that were adopted. 


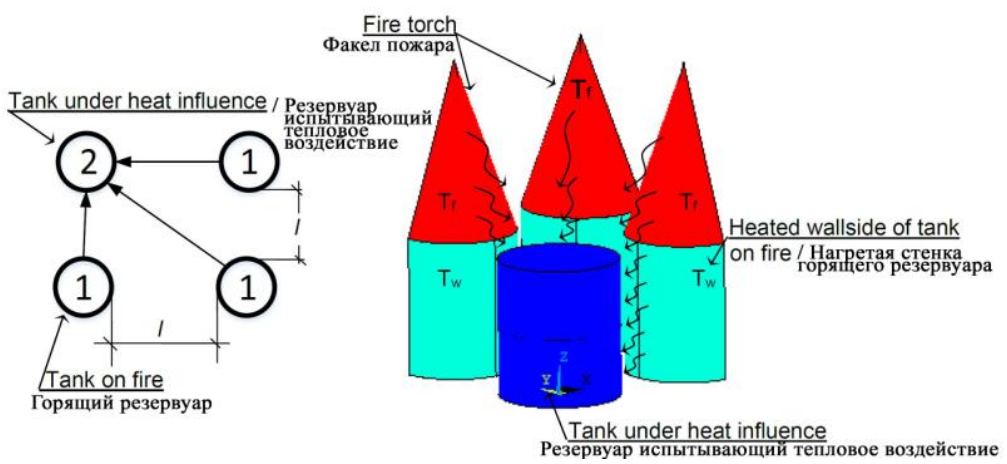

Fig. 2. The third scheme of mutual situation of tanks with and without fire.

We also had reviewed the internal structure of the tank available in its oil. That is in addition to heat radiation from the fire plume was seen inside the reservoir heat transfer in the cavity between mirror petroleum product and the inner wall of the tank. Fig. 3 shows the heat exchange between the mirror petroleum product and the inner wall of the tank.

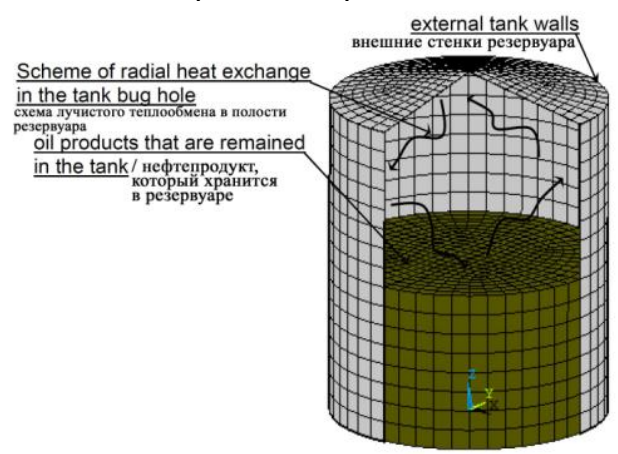

Fig. 3. The internal structure of the tank and the scheme of heat exchange in the bug hole between the walls and mirror oil products liquid.

Fire scenario foresees two versions of fuel, that burns in the torch of fire - oil and gas, and the temperature of the torch will be equal to $1500 \mathrm{~K}$ and $1400 \mathrm{~K}$, accordingly. In addition, the variants of fire scenario foresee different levels of filling fuel tanks on 0.5 and 0.9 from the volume of the tank. To study the characteristics of heat exchange of fire torches, the distance between the tanks takes three values $-6 \mathrm{~m}, 10 \mathrm{~m}$ and $20 \mathrm{~m}$.

Considering the heat exchange between the torch and fire walls are used limiting conditions III of origin, which are responsible to Stefan-Boltzmann law [3 - 6].

For the calculation can be used non-stationary heat conduction equation. The heat conduction equation for three-dimensional calculation area can be written in this form [2 5]:

$$
C v(T) \frac{\partial T}{\partial t}=\frac{\partial}{\partial x}\left(\lambda(T) \frac{\partial T}{\partial x}\right)+\frac{\partial}{\partial y}\left(\lambda(T) \frac{\partial T}{\partial y}\right)+\frac{\partial}{\partial z}\left(\lambda(T) \frac{\partial T}{\partial z}\right),
$$

The thermal effect on the estimated tank area of the zone of high temperature, which is formed during the combustion of fuel in the torch, can be described limiting condition (LC) III origin, which is written as: 


$$
-\left.\lambda(T) \frac{\partial T}{\partial x}\right|_{x=0,3, M}=\alpha_{B}\left(T_{P}-T_{W}\right),
$$

$\alpha_{B}$ - radiative coupling factor, watt $/\left(\mathrm{m} \cdot{ }^{\circ} \mathrm{C}\right)$;

$T_{P}, T_{W \text { - }}$ accordingly temperature fire surroundings and surface of fire-prevention obstacles ${ }^{\circ} \mathrm{C}$;

$x$ - the current spatial coordinate.

Heat exchange coefficient is determined by using generalized equation, which expresses the Stefan-Boltzmann law [2 - 5]

$$
\sum_{j=1}^{N}\left(\delta_{i j}-\varphi_{i j}\right) \quad \sigma T_{j}^{4}=\sum_{j=1}^{N} \frac{1}{A_{j}}\left(\frac{\delta_{i j}}{\varepsilon_{j}}-\varphi_{i j} \frac{1-\varepsilon_{i}}{\varepsilon_{j}}\right) q_{j},
$$

$\delta_{\mathrm{ij}}$ - parameter, which equals 0 , if $i \neq j$, and equals 1 , if $i=j$;

$q_{j}$ - surface heat flux through $i$ surface, which exchanges radiations with $j$ surface

$\varphi_{i j}$ - radiation shape forms, dependent on mutual situation $i$ and $j$ surface squares, which exchange radiation and are defined by integral equation of radial heat exchange between surfaces, which radiate heat:

$$
\varphi_{i j}=\frac{1}{A_{i}} \int_{A_{i}} \int_{A_{j}} \frac{\cos \theta_{i} \cos \theta_{j}}{\pi r^{2}} d A_{j} d A_{i},
$$

$\theta$ - angle between the normal to the element and the line, which connects elements $i$ and $j$; $r$ - distance between elements' $i$ and $j$ centers.

\section{Material and methods}

Non-stationary heat conduction equation (1) may be approximated with the help of finite elements method [7, 8]. For the given case during equation solving by means of finite elements method, the system of nonlinear equation is applied. It looks the following way in matrix formulation:

$$
[K(T)]\{T\}=\{Q(T)\}
$$

where $[K(T)]$ - generalized matrix of material coefficients; $\{Q(T)\}$ - vector of main outer heat fluxes.

During consideration of inner and outer heat fluxes equality, the given system is supplemented and formulated more generally:

$$
\{P(T)\}=\{Q(T)\}
$$

where $\{P(T)\}$ - vector of main outer heat fluxes, conditioned by gridded model parameters.

The given system of equations is solved with help of Newton-Raphson integration method. During conduction of integrations the disconnection must be minimized:

$$
\{\Phi\} \equiv\{Q(T)\}-\{P(T)\} \rightarrow\{0\} .
$$

Newton-Raphson method is realized during application of cut off Taylor series to nullity vector.

During conduction of such procedures linearization of equation system (5) is reached in the following way:

$$
\left[K_{T}^{(i-1)}\right]\left\{\Delta T^{(i)}\right\}=\left\{Q^{(i)}\right\}-\left\{P^{(i-1)}\right\},
$$

For solution of equation system equilibria integrations are done $(i=1,2,3 \ldots)$, and new temperature indexes are determined on every integration of equation:

$$
\left\{T^{(i)}\right\}=\left\{T^{(i-1)}\right\}+\left\{\Delta T^{(i)}\right\}
$$

The iterations are carried out to achieve acceptable convergence. 
In equation (9), the matrix $\left[\mathrm{K}_{\mathrm{T}}\right]$ is called tangent matrix or Jacobian. The coefficients of this matrix are determined by the following equation:

$$
\left[K_{T}^{(i-1)}\right] \equiv\left(\frac{d\{\Phi\}}{d\{T\}}\right)_{i-1}
$$

$\{\mathrm{F}\}$ vector decomposed in a truncated Taylor series and is as follows

where $\left\{\Delta T^{(i)}\right\}=\left\{T^{(i)}\right\}-\left\{T^{(i-1)}\right\}$.

$$
\left\{\Phi^{(i)}\right\} \cong\left\{\Phi^{(i-1)}\right\}+\left(\frac{d\{\Phi\}}{d\{T\}}\right)_{i-1}\left\{\Delta T^{(i)}\right\},
$$

Nonlinear setting heat equation use Newton-Raphson method in combination with the method of integration over time, which allows you to record the original system of equations in the following form

$$
\left[\bar{K}^{(i-1)}\right]\left\{\Delta T^{(i)}\right\}=\left\{\mathrm{Q}^{(i)}\right\}-\left\{\bar{P}^{(i-1)}\right\},
$$

where $[\bar{K}]$ - equivalent conductivity matrix; $\{\bar{P}\}$ - equivalent internal heat flux vector

In equation (5) $\{Q(T)\}$ - vector nodal heat flow, which is determined by external override vector set of heat flow $\left\{Q_{0 n}\right\}$ equivalent matrix and thermal conductivity $[\bar{K}(\mathrm{~T})]$. $\{\bar{P}\}$ - equivalent nodal vector of the internal heat flow, which is defined in the override equivalent thermal conductivity of the matrix $[\bar{K}(\mathrm{~T})]$, determined at the time of numerical integration vector $\left\{\Delta T^{(i)}\right\}$ Euler method with using the formula

$$
\left\{T_{n+1}\right\}-\left\{T_{n}\right\}=\Delta t_{n}(1-\varsigma)\left\{T_{n}\right\}+\Delta t_{n} \varsigma\left\{T_{n+1}\right\},
$$

where $\Delta t_{n}-$ step integration over time;

$\zeta$ - Euler parameter equal to 0,5 for the available computational scheme CrankNicholson.

The equivalent conductivity matrix $[\bar{K}(\mathrm{~T})]$ determined by the expression

$$
\left[\bar{K}_{n}(T)\right]=\frac{1}{\varsigma \cdot \Delta t_{n}}\left[C_{n}(T)\right]+\left[K_{n}(T)\right]
$$

where $\left[\mathrm{C}_{n}(\mathrm{~T})\right]$ and $\left[K_{n}(\mathrm{~T})\right]$ - according heats matrix and thermal conductivity.

To override $\{Q(T)\}$ we use the expression

$$
\left\{Q_{n}(T)\right\}=\left\{Q_{0 n}\right\}+\frac{1-\varsigma}{\varsigma}\left[C_{n}(T)\right]\left\{T_{n}\right\}-\left[K_{n}(T)\right]\left\{T_{n}\right\} .
$$

$\left\{Q_{0 n}\right\}$ - vector set of external heat flow, which is defined as:

$$
\left\{Q_{0 n}\right\}=\left\{Q_{n}^{\text {conv }}\right\}+\left\{Q_{n}^{\text {rad }}\right\},
$$

where $\left\{Q_{n}^{\text {conv }}\right\}$ - current vector nodular surface convective heat flow, which are defined as follows:

$$
\left\{Q_{n}^{\text {conv }}\right\}=\alpha_{\kappa}\left(\left\{T_{W n}\right\}-\left\{T_{P n}\right\}\right) A_{e}
$$

$\left\{Q_{n}^{\text {rad }}\right\}$ - current radiant surface vector of nodal heat flow, which is defined as follows

$$
\left\{Q_{n}^{\text {rad }}\right\}=\varepsilon \sigma\left(\left\{T_{W n}^{4}\right\}-\left\{T_{P n}^{4}\right\}\right) A_{e} .
$$

$\left\{T_{W n}\right\}$ - vector of nodal surface temperatures; 
$\left\{T_{P n}\right\}$ - vector, which members are equal to the temperature of the fire surroundings, determined with the help of the appropriate temperature regime.

Initial data which is used in accordance with $[8,9]$ for payments reduced to the Table. 1.

Table 1. Initial data for calculation of the temperature distribution in the system of tank wall - torch burning.

\begin{tabular}{|c|c|c|c|c|c|c|}
\hline ט゙ & 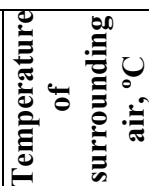 & 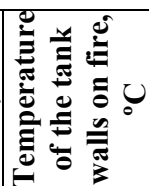 & 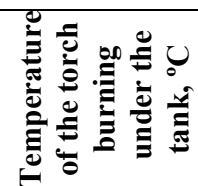 & 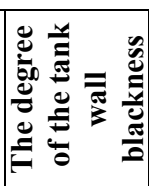 & 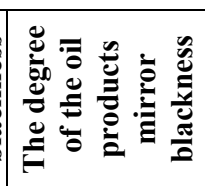 & 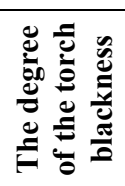 \\
\hline \multirow{4}{*}{20} & \multirow{4}{*}{20} & \multirow{4}{*}{225} & Petrol & \multirow{4}{*}{0.9} & \multirow{4}{*}{0.8} & \multirow{4}{*}{1} \\
\hline & & & 1127 & & & \\
\hline & & & $\begin{array}{l}\text { Oil } \\
1227\end{array}$ & & & \\
\hline & & & 1227 & & & \\
\hline
\end{tabular}

Using the accepted mathematical tools, we designed calculation methodology for the implementation of the calculation according to scenarios of fire which was described above. According to this method the calculation is based on such procedures.

1. The geometric model with application of the boundary conditions is constructed according to Fig. 2 .

2. The cycle is organized, during which the time of thermal fire effect is changed.

3. The time of thermal fire effect is $60 \mathrm{~min}$, as far as the previous calculation has shown that the thermal process is set within this time.

4. The calculation is repeated for the tank with another scenario of thermal fire effect.

Thermal properties of steel and petrol can be taken according to recommendations [8 9]. According to these recommendations adopted thermal characteristics are given in Table. 2

Table 2. Thermal petrol and steel characteristics.

\begin{tabular}{|c|c|c|}
\hline $\begin{array}{c}\text { Heaf-transfer } \\
\text { coefficient, } \\
\lambda(\mathbf{T}), \text { watt } /\left(\mathbf{m} \cdot{ }^{\circ} \mathrm{C}\right) \\
\end{array}$ & $\begin{array}{c}\text { Specific heat capacity, } \\
c_{p}(T), \mathrm{J} /\left(\mathrm{kg} \cdot{ }^{\circ} \mathrm{C}\right)\end{array}$ & $\begin{array}{c}\text { Density, } \\
\mathrm{kg} / \mathrm{m}^{3}\end{array}$ \\
\hline \multicolumn{3}{|c|}{ Thermal steel characteristics } \\
\hline $\begin{array}{c}\lambda=54-3.33 \cdot 10^{-2} \mathrm{~T} \\
\text { at } 20^{\circ} \mathrm{C} \leq \mathrm{T} \leq 800^{\circ} \mathrm{C} \\
\lambda=27,3 \\
\text { at } 800^{\circ} \mathrm{C}<\mathrm{T} \leq 1200^{\circ} \mathrm{C}\end{array}$ & $\begin{array}{c}c_{p}=425+0,773 \mathrm{~T}-1.69 \cdot 10^{-3} \mathrm{~T}^{2}+2.22 \cdot 10^{-6} \mathrm{~T}^{3} \\
\text { at } 20^{\circ} \mathrm{C} \leq \mathrm{T} \leq 600^{\circ} \mathrm{C} \\
c_{p}=666-13002(\mathrm{~T}-738)^{-1} \\
\text { at } 600{ }^{\circ} \mathrm{C}<\mathrm{T} \leq 735^{\circ} \mathrm{C} \\
c_{p}=545-17820(\mathrm{~T}-731)^{-1} \\
\text { at } 735^{\circ} \mathrm{C}<\mathrm{T} \leq 900^{\circ} \mathrm{C} \\
c_{p}=650 \text { at } 900{ }^{\circ} \mathrm{C}<\mathrm{T} \leq 1200^{\circ} \mathrm{C} \\
\end{array}$ & 7850 \\
\hline \multicolumn{3}{|c|}{ Thermal petrol characteristics } \\
\hline 1,1 & 2740 & 768 \\
\hline
\end{tabular}

\section{Results}

After payment for the methods we have developed results in a temperature distribution. Picture temperature distributions at different times for third scenarios of fire (torch temperature $1400 \mathrm{~K}$ ) are shown in Fig. Fig. 4 and 5. 


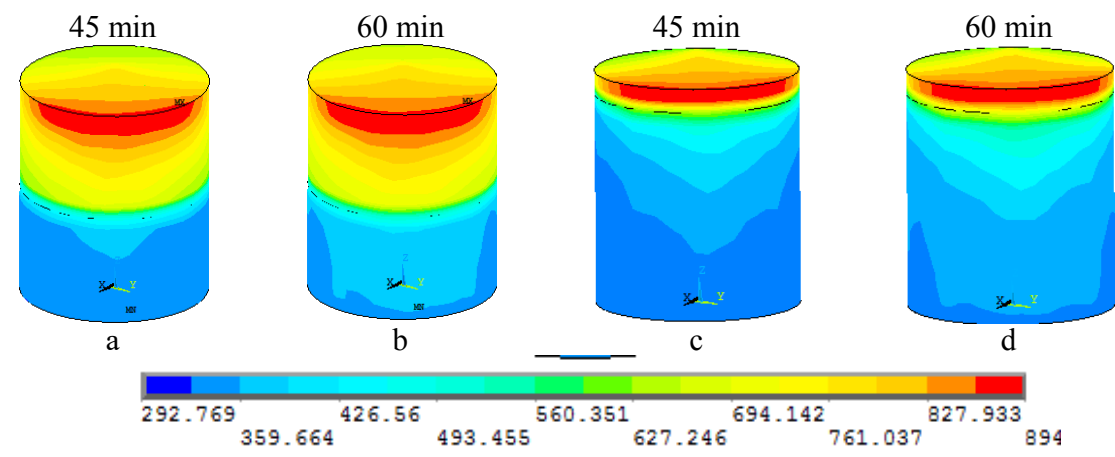

Fig. 4. Temperature distribution on external wallside of tank with thermal fire effect according to the third scheme with its space filling at $50 \%(\mathrm{a}, \mathrm{b})$ and $90 \%(\mathrm{c}, \mathrm{d})$ at $l=6 \mathrm{~m}$.

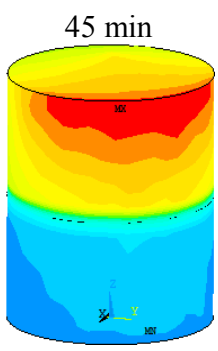

a

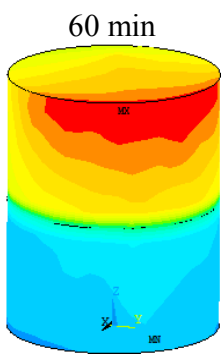

$\mathrm{b}$

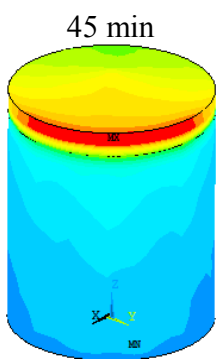

c

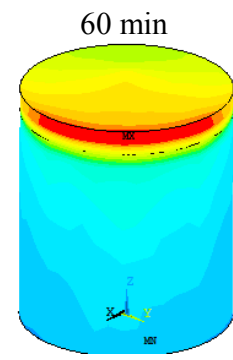

$\mathrm{d}$

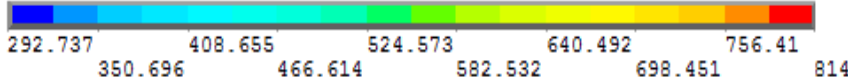

Fig. 5. Temperature distribution on external wallside of tank with thermal fire effect according to the third scheme with its space filling at $50 \%(\mathrm{a}, \mathrm{b})$ and $90 \%(\mathrm{c}, \mathrm{d})$ at $l=10 \mathrm{~m}$.

Analysis of temperature distribution, which is presented on the figures below, shows that the most dangerous is the scenario when the fire is going on according to the third scheme, when the oil torch is burning at $1500 \mathrm{~K}$.

The most dangerous scenario for any space filling and any torch petrol happens if the tanks on fire are situated according to the 3 schemes (refer to fig. 2). Fig. 6 shows the curves of maximal temperature of tank's wallside heating in different schemes of adjoining tanks on fire situation.
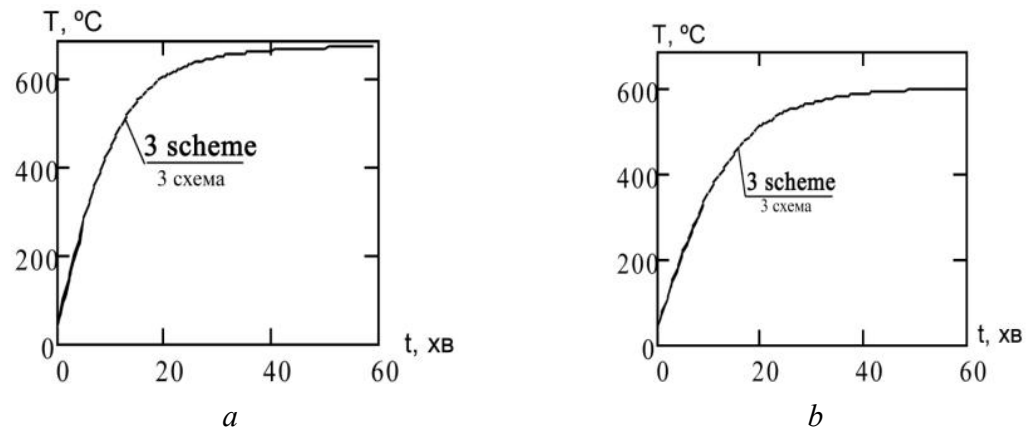

Fig. 6. Curves maximum heating temperature of the walls of the tank depending on the exposure time of fire on allied tanks located on third scheme at distances from this reservoir: $\mathrm{a}-6 \mathrm{~m} ; \mathrm{b}-10 \mathrm{~m}$. 
If the tank is space filled at $90 \%$, the character of graphics of maximal temperature of tank's wallside heating, which has a contact with oil product, depending on the distance between the tanks, repeats the character of graphics shown at fig. 13.

For construction of regressive dependencies, it was determined that they must respond to second order polynomial. Using the approach of minimization of mean square residual, regression coefficients were determined. They are shown in tab. 3.

Table 3. Regression coefficients mean maximum temperature of the outer surface of the tank wall on the distance between reservoirs.

\begin{tabular}{|l|c|c|c|c|}
\hline $\begin{array}{l}\text { Regression coefficients / } \\
\boldsymbol{T}(\boldsymbol{l})=\boldsymbol{a}_{\mathbf{0}}+\boldsymbol{a}_{\mathbf{1}} \boldsymbol{l}+\boldsymbol{a}_{\mathbf{2}} \boldsymbol{l}^{\mathbf{2}}, \mathbf{}^{\mathbf{0}} \mathbf{C}\end{array}$ & $\boldsymbol{a}_{\mathbf{0}}$ & $\boldsymbol{a}_{\mathbf{1}}$ & $\boldsymbol{a}_{\mathbf{2}}$ & Error, \% \\
\hline oil torch tank filled to 50 \% & 789.608 & -27.895 & 0.609 & 0.3 \\
\hline petrol torch tank filled to 50 \% & 675.135 & -11.286 & 0.026 & 0.25 \\
\hline oil torch tank filled to 90 \% & 817.9 & -33.99 & 0.794 & 0.33 \\
\hline petrol torch tank filled to 90 \% & 741.699 & -29.184 & 0.669 & 0.31 \\
\hline
\end{tabular}

The data can be used for predicting the heating temperature of the walls of the tank, depending on the distance between the reservoirs.

\section{Conclusions}

Given the studies the following conclusions.

1. Completed mathematical modeling of heat in the fire in the warehouse of petroleum products, where they are stored in tanks involving energy radiation heat transfer equation and unsteady heat conduction equations and finite element method.

2. Because of mathematical modeling of thermal processes in a fire on tank farms identified patterns of heating surfaces of the walls of the reservoir of petroleum products on the degree of completion, type of fuel burning in flares on the tanks and the distance between them.

3. Revealed that the most dangerous reservoirs layout is the third scheme (see. Fig. 6) when filling the tank by $50 \%$ and crude oil burning in the flare of the reservoirs in case of fire.

4. Were built regressive dependence of maximum temperature of the tank wall outer surface and internal wall which are in contact with the oil products.

5. The regressive dependences that were received can be used for the design of oil depot in choosing tanks geometric parameters and the distances between them.

\section{References}

1. M.M. Semerak, S.V. Pozdeyev, R.S. Yakovchuk, V.V. Chernetskyi, Fire safety: Collection of scientific works. - Lviv: LDU BZD 29 (2016)

2. B.V. DSTU B.V. 2.6-183:2011 Kiev: Ukraine State Building (2011) (in Ukr.)

3. A.N. Tikhonov Moskva: Vysshaya shkola (1976) (in Rus)

4. A.A. Samarskyj Moskva: Nauka (1971) (in Rus)

5. A.A. Samarskyj, P.N. Vabyshhevych Moskva: Edytoryal URSS (2003) (in Rus)

6. E.A. Vlasova, V.S. Zarubyn, G.N. Kuvyrkyn, Moskva: MGTU im. Baumana (2001)

7. A.S. Saharov, V.M. Kyslookyj, V.V. Kyrychevskyj, Kiev: Vysshaya shkola (1982)

8. ANSYS, ANSYS 9.0 Manual Set

9. EN 1994-1-2:2005 